RAJETÓRIAS

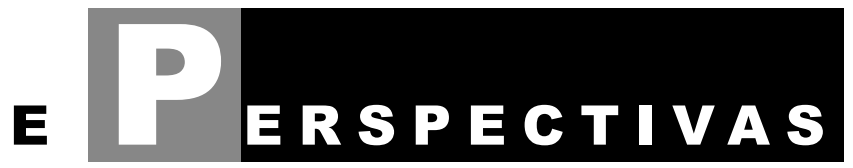





\section{Crianças, Povos Indígenas e Direitos: controvérsias identitárias e sensibilidades jurídicas a partir de Belo Monte ${ }^{1}$}

Children, Indigenous Peoples and Rights: identity
controversies and legal sensitivities from Belo Monte Jane Felipe Beltrão

Antropóloga, historiadora, professora titular, docente permanente dos programas de pósgraduação em Antropologia (PPGA) e Direito (PPGD) da Universidade Federal do Pará (UFPA) e docente colaboradora do Programa de Antropologia Social (PPGAS) da Universidade de Mato Grosso do Sul (UFMS). Bolsista de produtividade em pesquisa do Conselho Nacional de Desenvolvimento Científico e Tecnológico (CNPq) nível 1C. E-mail: janebeltrao@gmail.com.

\section{Resumo:}

Os efeitos sociais produzidos pela instalação da Usina Hidrelétrica de Belo Monte no Rio Xingu (Altamira-Pará) repercutem, ainda hoje, em Altamira e nos diversos municípios vizinhos, efeitos que afetam sobremaneira a vida de moradores/as, especialmente aqueles/as que vivem na chamada Volta Grande do Xingu e as margens do Rio Xingu, em especial os povos e populações tradicionais que tiveram seus territórios uma vez mais dilacerados, sendo obrigados a deslocamentos forçados. A situação torna-se a cada dia mais crítica, comprometendo o presente e o futuro de crianças que têm suas identidades e infâncias afetadas por sensibilidades jurídicas que "não lhes permite a vida segundo seus próprios termos". Os "sequestros brancos" de indígenas crianças e as imposições de um sistema jurídico hegemônico produzem inicialmente pânico e, na sequência, ações pautadas pelo "humanismo etnocêntrico"; a cada passo, violam-se os direitos diferenciados - étnicos ou não -, desrespeitando e corroendo a legislação nacional e internacional.

Palavras-chave: Indígenas Crianças, Povos Indígenas, Direitos, Sensibilidades Jurídicas.

\footnotetext{
A primeira versão do texto foi apresentada sob a forma de palestra dialogada proferida a convite do Programa de Pós-Graduação em Antropologia (PPGAS) da Universidade Federal Fluminense (UFF), juntamente da Comissão de Direitos Humanos da Associação Brasileira de Antropologia (ABA), com apoio do Instituto de Estudos Comparados de Administração de Conflitos (INEAC), em 9 de março de 2018, no Campus Gragoatá em Niterói, Rio de Janeiro.
} 


\section{Abstract:}

The social effects produced by the installation of the hydroelectric plant of Belo Monte on the Xingu River (Altamira, Pará) still reverberate in Altamira and the various neighboring cities; effects that greatly affect the lives of residents, especially those living in the so called Volta Grande and Xingu river banks, specially the traditional populations who have had their territories torn apart once again, obliged to forced displacement. The situation becomes more critical every day, jeopardizing the present and future of children who have their identities and childhood affected by legal sensitivities that "do not allow them to live on their own terms". The "white kidnappings" of indigenous children and the imposition of a hegemonic legal system initially produces panic, followed by actions based on the "ethnocentric humanism" and with each step, differentiated rights are violated - ethnic or otherwise - disrespecting and eroding the national and international legislation.

Keywords: Indigenous Children, Indigenous Peoples, Rights, Legal Sensitivities.

\section{ANTROPOLOGIA EM AÇÃO E TRAJETÓRIA ACADÊMICA NA AMAZÔNIA²}

A performance e a escrita de uma trajetória, feita em primeira pessoa, pela interessada em apresentá-la ao público, passa pela possibilidade de refletir e produzir reconstruindo passo a passo um percurso que possui como fio condutor a experiência de uma formação a um só tempo singular e coletiva. Singular porque parece única, vivida apenas pela pessoa que escreve, entretanto é coletiva, na medida em que certos aspectos se fazem presentes na carreira de muitas outras profissionais, ${ }^{3}$ que se encontram no mesmo campo de

\footnotetext{
O texto contém excertos do Memorial que escrevi por ocasião do Concurso para Titular na Universidade Federal do Pará (UFPA), em 2017, intitulado Trajetória em Antropologia na Amazônia, ainda inédito.

3 Considero que há diferenças substanciais na trajetória de profissionais, especialmente quando somos mulheres, pois o gênero interfere na construção do conhecimento e, no mínimo, dificulta a instituição da carreira de uma antropóloga. Sobre o assunto, consultar: SANTOS, Lucy Woellner dos; ICHIKAWA, Elisa Yushie; CARGANO, Doralice de Fátima (Orgs). Ciência, tecnologia e gênero: Desvelando o Feminino na Construção do Conhecimento. Londrina/PR: IAPAR, 2006.
} 
atuação e até em outros, nos quais as condições de estudo e trabalho podem ser idênticas. Contudo, acasos e imprevistos parecem tomar a dianteira e oferecer representação impar do percurso.

Considerando o alerta, a tarefa de apresentar a trajetória exige cuidado redobrado na escrita do documento, em sua apresentação e, sobretudo, na "defesa" das memórias escritas diante do público leitor, pois, por maior que seja o esforço da autora, os "escritos de si" revelam a trajetória, mas ao mesmo tempo deixam outras "histórias em suspenso", uma vez que, no afã de evitar que o documento se assemelhe, de alguma forma, a uma caixa de curiosidades de algum museu do passado, omite-se aquilo que nos incomoda. Portanto, a trajetória produzida é parte da memória que me permiti revelar, na tentativa de informar sobre meu caminho pessoal e profissional na Antropologia em Ação.

Sou a mulher a quem o tempo ensinou a viver em voz alta, pois nasci na Amazônia, onde os sussurros nos assustam diuturnamente. Assim sendo, antes de tudo, fui obrigada a lutar para estudar e me fazer profissional. Na política, minha formação compreende combate ininterrupto contra os colonialismos $^{4}$ que se fazem presentes de muitas formas. Portanto, sou acadêmica porque militante e vice-versa.

Cedo, encontrei o caminho da Antropologia, que me oferecia a oportunidade de lidar com direitos, sem precisar ser operadora do Direito, no sentido estrito da categoria. O tempo colocou-me no campo do Direito como profissional da Antropologia. As histórias serão vistas por conta de como cheguei a escrever o artigo aqui apresentado.

Hoje, reuni os dois campos Antropologia e Direito, os quais são lastreados pela formação em História, em uma carreira de 36 anos em uma Universidade, como a Federal do Pará, onde o futuro é agora. Creio que, com as oportunidades "criadas" ou conquistadas, fico confortável para deliberar e trabalhar com direitos diferenciados entre povos indígenas e tradicionais. Entre os/ as interlocutores com quem dialogo, não escolhi este ou aquele/a protagonista, o povo x ou y; fui de certa forma escolhida para a prática da Antropologia

Discuto os colonialismos desde a publicação de: STAVENHAGEN, R. 1981 [1965]. Siete Tesis Equivocadas sobre América Latina. Sociología y Subdesarrollo. México, Nuestro Tiempo, p. 15-84. 
em Ação. O primeiro tema que me assombrou foram os direitos territoriais, ${ }^{5}$ depois vieram os crimes ocorridos em terras indígenas, ${ }^{6}$ mais adiante surgiu a adoção de pessoas indígenas, ${ }^{7}$ entre tantos outros temas que enfrentei como perita, construindo laudos e vistorias por solicitação do Ministério Público Federal (MPF), dos povos indígenas e do poder judiciário.

Muitas foram as demandas, inúmeras foram as vistorias, as denúncias, as audiências e as peças que construí, os livros que escrevi ouvindo cada protagonista, ao longo da minha trajetória. Aos povos indígenas e quilombolas devo escutas, narrativas, compartilhamentos e denúncias acerca da violência e das violações que enfrentam com muita luta dentro do quadro de fricção interétnica que, na Amazônia, é desafio diário.

Hoje, como no passado, os direitos continuam desrespeitados, apesar da agência que protagonistas indígenas e/ou quilombolas empreendem. Entre os direitos dificilmente respeitados, encontram-se as situações de violência enfrentadas por mulheres étnica e racialmente discriminadas e sujeitas a violações e violências de gênero, pelas quais as mulheres "pagam com o corpo" o fato de não se garantir direitos diferenciados. ${ }^{8}$

A tessitura de uma Antropologia em Ação voltada a povos indígenas e populações tradicionais, em tempos contemporâneos, exige costurar finos

5 Escrevi um laudo sobre os Gavião/Parkatêjê e a BR 222, e outro para os Suruí/Aikewára e a BR 153, ambos inéditos.

6 Cf. BELTRÃO, J. F. 2002. Haraxare Krokti Ronore Konxarti e a Vigilância do Território Gavião Parkatêjê - Laudo antropológico. Humanitas, Belém, v. 18, n. 1, p. 101-111; BELTRÃO, J. F.; MASTOP-LIMA, L. de N.; MOREIRA, H. L. F. De vítimas a indiciados, um processo de ponta-cabeça: Suruí Aikewára versus Divino Eterno - Laudo antropológico. Espaço Ameríndio, UFRGS, v. 2, p. 194-258, 2008. E, ainda, BELTRÃO, J. F. Direitos humanos e povos indígenas: um desafio para a Antropologia. In: COSTA, P. S. W. A. (Org.). Direitos Humanos em Concreto. Curitiba, PR: Juruá Editora, 2008, p. 157-174.

7 Fiz dois laudos (2017) sobre adoção de crianças (dois meninos e duas meninas) entre povos indígenas, denominados Entre os Araweté e os Asurini: laços de solidariedade, ainda inéditos, cujos excertos tenho usados em alguns artigos.

8 Sobre o assunto, consultar: BELTRÃO, J. F.; BARATA, C. G. C. B.; ALEIXO, M. T. Corporeidades silenciadas: reflexões sobre as narrativas de mulheres violadas. Revista Direito e Práxis. v. 8, p. 592-615, 2017; BELTRÃO, J. F. Indígenas e quilombolas em situação de violência: como garantir direitos diferenciados? Revista de Antropologia. v. 54, p. 204-213, 2016a; BELTRÃO, J. F. Indígenas e Quilombolas: crianças em circulação ou em situação de violência? Revista Mundaú, v. 1, p. 91-102, 2016b; e, ainda, BELTRÃO, J. F. Cunhatãs de uso comum, segredos guardados em Igaçabas ou direitos de indígenas meninas violadas. In: VELlOSO, E. A.; FONSECA, L. C. da; Chichovski, Patrícia Blagitz (Org.). Direitos Humanos na Amazônia. Salvador/Bahia: JusPODIVM/ CESUPA, 2017, p. 89-106. 
retalhos de muitas histórias um a um para formar uma colcha de retalhos estruturada, na qual enlace e envolva os/as muitos/as parceiros/as e aliados/ as. No Brasil, os fazeres das múltiplas antropologias se imbricam, há algum tempo, na interlocução com os povos tradicionais, em especial com indígenas e quilombolas, sobretudo em tempos contemporâneos temerosos, quando a violação dos direitos étnicos e raciais não assina armistício, a guerra é empreendida dia após dia. Evidentemente, o trabalho reforça o compromisso político com os povos indígenas e tradicionais, conforme os cânones do código de ética da Associação Brasileira de Antropologia (ABA), especialmente quando se integra a Comissão de Direitos Humanos, coordenada por Lucía Eilbaum.

É importante asseverar que as circunstâncias encontradas na Universidade Federal do Pará favorecem minha atuação ainda hoje, pois ao longo da última década o diálogo entre os protagonistas indígenas e quilombolas e as diversas autoridades acadêmicas foi feito com algum sucesso, uma vez que os intelectuais indígenas formados/as na Instituição aceitam o desafio de indicar caminhos para a melhoria das políticas afirmativas, adotadas na Instituição, e para a atuação conjunta nas áreas do ensino, da pesquisa e da extensão, posto que as políticas afirmativas exigem iteração e discussão qualificada sobre o tema, quando a proposta é diversidade e inclusão social.

Ao voltar-se para o contexto regional, a UFPA não pensa apenas no Pará, daí a necessidade de destacar a importância da aliança e da interlocução com os povos indígenas, diálogo que ultrapassa a cidade universitária e as fronteiras da capital (Belém), e até do estado do Pará, pois se desenvolve a partir dos campi da UFPA que se espalham pelo interior do estado. O entrelaçamento, Educação, História, Antropologia e Direito reflete o compromisso que os/as profissionais da UFPA - entre os quais me incluo - historicamente devem aos povos tradicionais, por dever de ofício.

Considero Antropologia em Ação diferentes comportamentos que vão das ações comprometidas à escrita e com/sobre os direitos humanos, correspondendo a produtos diversos - solicitados ou não pelos coletivos indígenas 
e quilombolas; que podem ter ou não feição acadêmica, seja ela feita sob a forma de laudos e vistorias antropológicas; em parcerias relativas às intervenções sociais; por intermédio de artigos que revelam violências e violações; bem como a partir de livros didáticos e paradidáticos escritos "com e para" os povos tradicionais. Entretanto, as possibilidades são infinitas e cabe a cada antropólogo/a comprometido/a pensar as suas formas de ação na Antropologia, pois sempre há tempo para ações pertinentes.

\section{DE CONVERSAS EM MEIO A CONFLITOS}

Discutir criança, povos indígenas e direitos é demasiadamente amplo, razão pela qual se tenta trabalhar casos de indígenas aos quais é possível nomear como crianças e/ou jovens, moradores da região do Médio Xingu, área "conflituada" pela instalação da Usina Hidrelétrica de Belo Monte, visto que as noções sobre o que é a justiça e sobre as maneiras como ela deve ser exercida, "distribuída" referem-se a concepções diferenciadas que correspondem a cada sociedade conforme o saber local, como indica Geertz. (1998)

Faz-se urgente compreender que as variações de entendimento não se cingem, unicamente, aos graus de definição do que seja ou não Justiça; mas se impõem sobretudo pelo exercício do poder do Estado brasileiro, em nome de um suposto desenvolvimento, que se instaura sobre os processos da vida social de conteúdos específicos. Transformando símbolos, histórias e distinções usuais, produzindo o massacre dos povos etnicamente diferenciados.

A inversão de valores verificada no Médio Xingu, local onde se instalou a Usina Hidrelétrica de Belo Monte, nega aos povos tradicionais - sejam eles indígenas ou não - a possibilidade de continuarem a usufruir do lastro cultural e cosmológico que sustenta suas ações e convicções, procurando ocultar as pertenças aos territórios usurpados pelo Estado com os quais, sobretudo os povos indígenas, mantêm relação de natureza social.

Conhecer em detalhe alguns casos que consideram o relato de pessoas que se envolveram com a guarda e proteção de crianças, até a presente data, 
permite-nos lidar com sentimentos e emoções que, como diz Geertz (1998), indicam a sensibilidade jurídica que deve nortear ações de forma diferenciada e plural objetivando contribuir para a expressar a melhor possibilidade de Justiça, tomando como referência a contextualização dos fatos, os(as) agentes sociais, bem como as nuances do evento analisado.

\section{DO CASO DE INDÍGENAS CRIANÇAS NASCIDAS GÊMEAS}

$\mathrm{O}$ caso de indígenas crianças gêmeas que se passa a narrar ocorreu em situação de perícia antropológica na qual atuei como perita judicial, convocada por Juiz de Direito da $1^{a}$ Vara Cível e Infância e da Juventude da Comarca de Altamira no Pará. ${ }^{9}$ Como perita nos processos realizei a oitiva - autorizada pelo Juiz responsável pelos casos - das pessoas interessadas. ${ }^{10}$

Os pais narraram, com alguma dificuldade, o que significa o nascimento de gêmeos entre os Araweté. Segundo as informações obtidas o nascimento de gêmeos ameaça a comunidade que os recebe, especialmente porque as crianças não são constituídas de uma só vez, elas vão sendo constituídas no quotidiano e na relação que os pais mantêm entre si. A movimentação relativa à formação das crianças pode afetar as demais crianças que estão se formando a partir de outros pais, que circulam convivem no dia a dia na aldeia.

Pessoas gêmeas constituem ameaça à imagem humana, pois se confundem entre si e confundem os demais, ameaçando a individualização de cada pessoa "conformada" pelos/as araweté. Por outro lado, a cosmologia araweté, que se encontra em processo de transformação, dada a relação mantida com as demais sociedades indígenas e com a sociedade não indígena, aponta, no

9 Os casos são de conhecimento público, portanto a identidade das crianças, dos pais e do povo indígena não foi preservada. Posso afirmar que na mídia a inversão de valores e o desrespeito foram a tônica.

${ }_{10}$ Parte da narrativa que aqui apresento consta dos autos dos processos, uma vez que compõem o laudo antropológico denominado Entre os Araweté e os Asurini: laços de solidariedade que produzi à época e permanece inédito. 
momento, para a necessidade de se afastar os gêmeos da aldeia para evitar catástrofes, em atenção ao contexto de Belo Monte.

O nascimento, ao anunciar a catástrofe, requer a ajuda de terceiros para afastar as crianças da aldeia. No caso, os gêmeos meninos foram trazidos junto de sua mãe para Altamira dada a hemorragia que a acometia e a urgência que o caso exigia. As meninas gêmeas foram também removidas a Altamira pelo técnico de enfermagem, provavelmente sem autorização dos pais e/ou das lideranças indígenas. Entre os gêmeos meninos e as gêmeas meninas há um intervalo de tempo de sete meses.

Segundo as informações dos pais, o nascimento de gêmeos (casal, meninos e/ou meninas) traz consigo dificuldade para aldeia, especialmente porque, segundo a cosmologia, a partir do primeiro nascimento de gêmeos os demais tenderiam a ser de também, e, como as crianças devem ser afastadas do convívio diário, a sociedade araweté se extinguiria em pouco tempo.

$\mathrm{O}$ afastamento dos gêmeos também se relaciona ao esforço das mulheres no momento do parto, pois além de exigir maiores cuidados produz muito sofrimento, elas correm sério risco de vida. E sem a presença de mulheres a reprodução social do povo não acontece e o fato pode levar extinção do povo. Os araweté informaram que apenas no futuro, quando as crianças de hoje estiverem adultas, podem voltar de visita ou para permanecer na aldeia de origem.

Considerando as informações recebidas, perguntou-se se outras pessoas na aldeia de origem ou em outra aldeia do mesmo povo poderiam cuidar das crianças gêmeas. Os araweté informaram que não seria viável, pois ainda poderiam produzir infortúnio no lugar, caso esse fosse um lugar de pertença araweté. Portanto, há uma incompatibilidade entre gêmeos e o lugar de pertença dos araweté. Imagino que os araweté devem ter estranhado nossa insistência durante a oitiva e podem nos ter tomado como parvos, dada a forma de condução do evento, que exige afirmação de vontades e sua repetição para satisfazer as exigências de trazer a verdade à superfície. 


\section{DA CAPACIDADE INDÍGENA DE NEGOCIAR MUDANÇAS}

A epistemologia dos Araweté é não apenas diferenciada da não indígena, mas é sobretudo prática e fruto de observações diárias de si e seus parentes. ${ }^{11}$ Nossos interlocutores chegaram à sala da oitiva com uma proposta de solução costurada politicamente. Eles tinham entrado em contato com pessoas do povo Asurini com quem mantêm relações históricas, inclusive por pensarem que num passado distante foram um único povo. Nas negociações feitas entre os Araweté e os Asurini os laços de solidariedade se multiplicam e implicam trocas permanentes que alicerçam os laços de solidariedade.

Revelaram os Araweté que o cacique do povo Asurini e seus pais, todos/as moradores da aldeia Kwatinemu, estavam dispostos a receber as crianças. Desejam ter com eles os meninos gêmeos e também as gêmeas meninas. Os caciques são parentes consanguíneos (filho e pai); assim, as crianças vão conviver dentro de uma mesma família e na mesma aldeia. A escolha dos Araweté e o parentesco dos Asurini atendem a legislação no item que diz respeito à permanência dos irmãos no mesmo núcleo familiar; no caso, todas as crianças araweté permaneceriam juntas ao mesmo grupo familiar, concretizado o processo.

Diante da solução que se avizinhava, ainda insistimos em perguntas, pois é do conhecimento de muitos que inúmeras famílias indígenas, de diversas etnias do Médio Xingu, pensaram e solicitaram, em algum momento, ter consigo as crianças, pois, diferentemente do que se divulga, os povos indígenas acolhem e cuidam de suas crianças com desvelo, oferecendo tudo o que têm de melhor. Por outro lado, mantêm entre si laços de solidariedade. Não havia propriamente um cadastro de interessados/as em ter as crianças consigo, e também não nos cabia produzi-lo para não gerar expectativas vãs nos pretendentes. Respeitamos a escolha dos pais araweté.

\footnotetext{
${ }_{11}$ Aqui usa-se parente de forma ampla, como tratamento usual entre povos indígenas. Falam de parentes não apenas consanguíneos ou afins, mas para nomear os demais povos indígenas, por reconhecerem-se como iguais.
} 
Perguntou-se a eles se confirmavam a vontade de entregar as crianças aos Asurini, ao que responderam afirmativamente. Na sequência, enumerou-se cada etnia do Médio Xingu, interrogando os araweté sobre o interesse em entregar os/as filhos/as a elas, e a todas as interrogações eles responderam "não". Diante da nossa insistência, enumeraram as vantagens da entrega aos Asurini. Primeiramente, porque os Asurini moram relativamente próximos aos Araweté e assim eles poderiam visitar os/as filhos/as sempre que passassem pela aldeia, podendo levar presentes a eles; por outro lado conheciam os cuidados do o povo escolhido com seus/suas filhos/as. Além disso, são Tupi como eles, os Araweté. Perante tantas certezas e de respostas peremptórias, declinamos de apresentar outra solução em respeito a autonomia e autodeterminação dos povos indígenas.

Entretanto, considerando os coletivos indígenas, restou aos presentes perguntar sobre a possibilidade de conversar com os membros da comunidade, em reunião na aldeia, como se costuma fazer na tentativa de amenizar possíveis divergências, entretanto o cacique foi enfático ao dizer que seria um sofrimento a mais. Assim, considerando o acontecido, convencemo-nos de que ir à aldeia poderia produzir novas feridas, afinal os pais tinham indicado uma solução que, acredita-se, vem sendo gestada nos últimos sete meses (desde maio de 2016) quando nasceram os meninos gêmeos. Pensamos ainda que deslocar-se à aldeia seria desautorizar os pais e, sobretudo, o cacique, causando dificuldades de natureza política a pessoas a quem as suspeitas dos não indígenas produziram aflições causadas por acusações infundadas, às quais os Araweté estiveram atentos e negociando solução adequada em vista da transformação de suas atitudes nos quase cinquenta anos de permanente contato com não indígenas.

Diante da convicção dos Araweté encerramos a conversa e fomos em busca dos/as "escolhidos/as" como família de destino dos gêmeos. Sabe-se que a decisão e a escolha dos pais araweté em favorecimento dos asurini podem desagradar muitas famílias indígenas que desejavam para si as crianças, mas as alegações dos pais foram substanciais e convincentes, e cabe aos demais acatá-la. 


\section{DE VOLTA AO INÍCIO}

Considerando o alcance da mídia e das redes sociais e a situação dos gêmeos, as autoridades judiciarias elaboraram alguns itens que, como perita judicial, fui obrigada a responder. As perguntas demonstram preocupação das autoridades, mas ao mesmo tempo indicam também a ausência de entendimento das sensibilidades jurídicas Araweté e Asurini. Apresenta-se abaixo as perguntas e as respostas produzidas a partir das oitivas.

\section{Há embasamento cultural/cosmológico para o caso apreciado? (sic)}

Todas as sociedades, por mais diversas que possam parecer aos nossos olhos, possuem lastro cultural e cosmológico que sustentam suas ações e convicções. Numa sociedade, como a brasileira, que se pensa plural e diversa, pelo menos nas inscrições de sua Carta Magna - Constituição de 1988 -, precisa demonstrar isso quando os casos relativos às diferenças culturais se apresentam. Não apenas os Araweté possuem cultura e cosmologia específicas, como evidenciado nos casos que se analisa, mas demonstraram cabalmente a capacidade de negociar no momento da modificação de suas tradições.

Os Araweté são cônscios de suas responsabilidades; no momento em que permitem a retirada dos/as gêmeos/as, procuram visitá-los e, ao mesmo tempo, negociam a entrega de suas crianças para que elas não molestem a sociedade em que vivem. Em nenhum momento, houve declaração de que eles não desejavam seus/suas filhos/as, tanto que ao serem perguntados sobre o número de filhos/as sempre responderam incluindo os/as gêmeos/as, jamais os/as renegaram. Muitas vezes, na conversa que entabulamos, percebi os olhos rasos d'água pela difícil situação que enfrentam. Considero que os pais dos meninos criariam seus gêmeos, na aldeia, caso isso fosse permitido.

\section{Há possibilidade de reinserção das crianças na mesma aldeia ou etnia Arawete? (sic)}

Informou-se não existir tal possibilidade. A cosmologia muda aos poucos (lentamente) e os/as demais membros da aldeia podem se con- 
siderar ameaçados/as pelo infortúnio que gêmeos atraem. Creio, uma vez mais, que os pais criariam seus/suas filhos/as na aldeia - caso fosse possível - ou longe da aldeia se possibilidades lhes fossem abertas. $\mathrm{Na}$ verdade, os pais oscilavam entre ter os/as filhos/as nos braços e respeitar as regras araweté.

\section{É recomendável que as crianças permaneçam em Altamira/PA? Há risco na perma- nência em virtude da proximidade dos pais biológicos e da etnia Arawete? (sic)}

Respondeu-se que há risco de permanecer em Altamira; apesar de o espaço da Casa de Saúde Indígena (CASAI) não ser ideal, outros lugares não produziriam o atendimento que tem sido oferecido aos/as gêmeos/as. $\mathrm{O}$ risco maior talvez não seja a ameaça à saúde das crianças por viverem próximo a pessoas doentes, mas pelo fato de viver e criar-se sem referências indígenas. Os maiores - meninos gêmeos - são pouco visto pelos pais e, teoricamente, perderão as referências na medida em que crescem. As menores - meninas gêmeas - têm possibilidade de se fixar nos mais próximos e, no caso, os mais próximos são os membros da equipe da CASAI, portanto não indígenas. Essa realidade foge do que se passa nas aldeias e pode expropriar as crianças da pertença indígena.

Assevera-se que os Araweté "perderam" muitas de suas crianças para os não indígenas que sempre acreditam que é melhor que as pessoas indígenas fiquem sob posse de pessoas indígenas. É interessante que o mote dos/ as não indígenas é a possibilidade de estudar, mas os casos de crianças indígenas que se analisou na Amazônia paraense não apontam certezas; pelo contrário, acendem as lâmpadas relativas aos perigos que as crianças passam, pois pessoas indígenas - meninas e/ou meninos - são transformados em "crias da casa" e muitas vezes, violadas por terceiros (BELTRÃO, 2015, 2016a, 2016b e 2017).

Mesmo com as transformações sociais ocorridas, muito pouco mudou! Vale consultar Pinho e Oliveira (2013) e, ainda, Oliveira (2016 e 2014) sobre os efeitos sociais de Belo Monte quando tratamos de crianças e jovens em Altamira. 


\section{É possível a introdução das crianças em outra etnia indígena ou recomenda-se a adoção por família ocidental/tradicional ("brancos")? (sic)}

É perfeitamente possível, tanto que os Araweté construíram um caminho para as crianças com os membros da etnia Asurini. Acresce-se que de maneira adequada, porque a adoção por outra etnia não promoveria a expropriação da identidade indígena.

Do ponto de vista das relações interétnicas, analisando as possibilidades de adoção por famílias não indígenas, acredita-se absolutamente inadequada, tanto do ponto de vista das crianças, como do ponto de vista dos pais que desejam estar por perto dos/as filhos/as. No caso de famílias não indígenas isso é quase impossível, mesmo que crianças indígenas ou não indígenas adotadas tenham direito de conhecer seus pais biológicos, este direito não é garantido na prática; assim, a entrega de crianças indígenas a pessoas não indígenas é comprometedor do ponto de vista da expectativa dos pais. Afora, há o fato da alienação promovida em relação aos pais biológicos, que é sempre difícil. Imagina-se que no caso de pais indígenas há possibilidade de produzir afastamento definitivo.

Há uma corrente de boatos que se sustentam, via redes sociais, dando conta de que várias famílias não indígenas teriam interesse em adotar as crianças, mas ao que me consta elas não estão inscritas no cadastro nacional de adoção, portanto seria inviável tentar elegê-las, poder-se-ia produzir ilegalidades.

Supõem-se que muito foi dito aos pais das crianças sobre adoção por pessoas não indígenas, inclusive informando que estas poderiam entregar grande número de bens, fato que se afigura como uma "compra branca" pautada pela ilegalidade. Apesar da rede de fofocas, que se exercita como forma de controle social, não há comprovações do fato, mas valeria investigar. É amoral trocar pessoas por bens materiais, especialmente quando a compreensão do outro é escassa em relação as ilegalidades presentes do ponto de vista do sistema judiciário hegemônico. 


\section{Quais as recomendações dos Arawete sobre o caso? (sic)}

A única recomendação que é permitida, observando as normas legais e a autonomia indígena é escutar e entregar as crianças aos pais escolhidos pelos/ as Araweté, no caso a família asurini. Acredita-se que mesmo que outras pessoas desejem as crianças, observar o que é dito pelos pais é a melhor solução.

\section{DAS INTERFERÊNCIAS DE NÃO INDÍGENAS E SUAS CONSEQUÊNCIAS}

As perguntas feitas revelam, sem dúvida, certa preocupação das autoridades judiciárias, mas ao mesmo tempo indicam o preparo cuidadoso que todos/as deveriam ter enquanto profissionais para atuar num caso como o dos/ as gêmeos/as araweté.

Chamo atenção que os povos tradicionais, por mais diversos que possam parecer aos nossos olhos, possuem lastro cultural e cosmológico que sustentam suas ações, convicções e indicam pertenças aos territórios com os quais mantêm relação de natureza social. Embora tal afirmação nos inclua, enquanto pessoas não indígenas, parece que a cosmologia entre nós se encontra "esmaecida”. A constatação do esmaecimento da cosmologia presente entre nós, os/as não indígenas, é sempre negada pelo fato de nos apresentarmos como "civilizados", e pressupõe as inúmeras dificuldades que temos em compreender e respeitar os povos indígenas, pois os consideramos, em oposição a nós, como supostamente não civilizados.

Considera-se que a cosmologia muda aos poucos (diria eu, muito lentamente) e a dinâmica social implica a aceitação de novas possibilidades e/ou ressignificação de propostas mais antigas, ou, ainda, a "importação" de novas possibilidades de agir no mundo que gradualmente indicam as mudanças no universo cosmológico e, no caso, em área de conflito.

Os pais biológicos nem sempre são "ameaça” à família receptora, pelo menos em princípio. Até porque as crianças, mesmo adotadas, têm direito a conhecer suas histórias, assim evitando a “tragédia” produzida pela ocultação 
da origem biológica de crianças que transforma a família de origem em ré e a família de recepção em heroína, numa antinomia indesejável, fundamentada em senso comum.

Paira, entre os profissionais das varas da infância e da juventude, salvo as exceções de sempre, que, ao tratar da adoção de crianças - qualificadas como indígenas ou quilombolas -, em "mãos brancas", elas serão mais bem tratadas, o que na Amazônia e, talvez, em muitos outros lugares é uma inverdade.

Encontro-me impossibilitada de concluir; penso que cabe apresentar propostas que nos conduzam a uma reflexão profunda. Assim sendo, debruço-me agora sobre as condições que poderiam ter evitado as dificuldades e o sofrimento dos Araweté e que devem ser evitadas energicamente, pois de modo geral elas indicam a omissão do Estado brasileiro no que diz respeito à possibilidade de proteger e resguardar os direitos indígenas. A omissão é uma das muitas formas de violação de direitos étnicos.

Uma das falhas que produziu todo o alvoroço em relação aos/as gêmeos/ as araweté está relacionada ao atendimento pré-natal de gestantes da referida etnia. É de conhecimento público que o nascimento de gêmeos/as entre as mulheres da referida etnia é uma possibilidade real. Entretanto, mesmo conhecendo a situação, os/as agentes de saúde do Distrito Sanitário Indígena (DSEI) - compreendendo direção e trabalhadores que estão em campo - não podem "cruzar os braços" diante do problema. Há documentos de conhecimento público que informam: "sabe-se que há muita resistência entre esses índios [araweté] acerca destes exames [relativos ao pré-natal] especificamente o ultrassom pélvico transvaginal e o PCCU”'

É recomendável reverter o quadro e as dificuldades que impedem a realização do pré-natal, afinal é possível detectar com o estetoscópio o batimento de mais de um coração dentro do útero da mãe, e em nove meses há tempo de discutir o nascimento de gêmeos/as. A gravidez de gêmeos/as requer uma

\footnotetext{
12 Cf. a folha 109 do processo 0007245-27.2016.8.14.0005, referente aos meninos gêmeos. A afirmação é parte do relatório denominado: "Visita à etnia Araweté", realizada, em 2014, durante vinte dias. Pergunto: não é responsabilidade do DSEI trabalhar para reverter o quadro? O relatório foi feito há pouco menos de três anos e o problema é conhecido desde os anos 1970, portanto penso que houve omissão no caso das gravidezes das mulheres araweté.
} 
ultrassonografia para confirmar a possibilidade, portanto creio que há descaso das autoridades em saúde.

A dificuldade produzida pela divulgação de fotos de indígenas, desde o hospital público, onde foram atendidas a mãe e os gêmeos, usuários do sistema único de saúde, gerou informações desencontradas e racistas manifestadas por pessoas inescrupulosas, que creio que deveriam ter sido investigadas. Um procedimento do Ministério Público Federal pode inibir novas investidas. Entretanto, não se tem notícia de nenhum procedimento do gênero. O procedimento inadequado causou sofrimentos incalculáveis aos povos indígenas, inclusive porque algumas etnias não aceitam a reprodução de sua imagem.

É preciso tomar providências sérias junto aos serviços de saúde que atendem povos indígenas, pois, nos casos estudados, o vazamento de informações desencontradas termina por ferir as éticas diferenciadas dos povos indígenas e a nossa ética (dos/as não indígenas), especialmente por desconhecerem os costumes que arrogantemente acreditam conhecer. A divulgação de notícias desta natureza só aumenta o preconceito e a discriminação imputada aos indígenas há séculos. A ação que se pretende humanitária, preocupada com o destino das crianças, termina sendo de um etnocentrismo inaceitável.

A Fundação Nacional do Índio (FUNAI) precisa manter-se atenta ao povo Araweté, especialmente no que diz respeito à gestação de mulheres da referida etnia. Vale indicar, diferentemente do que se lê nas entrelinhas dos processos, o acompanhamento desses casos relativos à discussão sobre indígenas crianças por antropólogo/a da Instituição, pois muito poderia ter sido evitado caso o profissional da FUNAI se fizesse presente. Há na Instituição quadros capazes de produzir bom acompanhamento das situações.

Por outro lado, não se pode esquecer que no caso das meninas gêmeas elas foram retiradas da aldeia por um agente de saúde, sob a alegação de serem gêmeas. Feita entre nós, a ação seria tomada como sequestro, mas o funcionário não foi molestado por investigação alguma.

O prognóstico é de que os problemas devem se multiplicar e tendem a tornarem-se mais complexos, dado os empreendimentos e o desrespeito aos direitos fundamentais dos povos indígenas. 


\section{REFERÊNCIAS}

\section{Documentais}

Acervo de entrevistas da autora sobre os povos Araweté e Assurini.

1. BELTRÃO, Jane Felipe. Entre os Araweté e os Asurini: laços de solidariedade -Laudo antropológico requisitado em 18 de agosto de 2016, pela Juíza de Direito Titular Carolina Cerqueira de Miranda Maia, para o processo 0007245-27.2016.8.14.0005, e pelo Juiz de Direito Substituto, em 13 de janeiro de 2017, Marcello de Almeida Lopes, para o processo 0000076-52.2017.8.14.0005 ambos da 1a. Vara Cível e Infância e da Juventude da Comarca de Altamira/PA, 2017. (Inédito)

2. Depoimentos e narrativas orais dos protagonistas dos processos 000724527.2016.8.14.0005 e 0000076-52.2017.8.14.0005.

3. Informações escritas e verbais oferecidas por Uwira Xakriabá (William César Lopes Domingues).

4. Processo 0007245-27.2016.8.14.0005 e 0000076-52.2017.8.14.0005 ambos da 1a Vara Cível e Infância e da Juventude da Comarca de Altamira/PA.

\section{Bibliográficas}

1. BELTRÃO, Jane Felipe. Memorial: Trajetória em Antropologia na Amazônia. Belém, UFPA, 2017. (Inédito)

2. BELTRÃO, Jane Felipe. Cunhatãs de uso comum, segredos guardados em Igaçabas ou direitos de indígenas meninas violadas. In: VELOSO, Elísio Augusto; FONSECA, Luciana Costa da; CHICHOVSKI, Patrícia Blagitz. (Org.). Direitos humanos na Amazônia. Salvador/Bahia: JusPODIVM/ CESUPA, 2017. p. 89-106.

3. BELTRÃO, Jane Felipe. Indígenas e quilombolas em situação de violência: como garantir direitos diferenciados? Revista de Antropologia, v. 59, n. 3, p. 204-213, 2016a. Disponível em: http://bit.ly/2F2j3pM.

4. BELTRÃO, Jane Felipe. Indígenas e quilombolas: crianças em circulação ou em situação de violência? Revista Mundaú, v. 1, p. 91-102, 2016b. Disponível em: http://bit.ly/2Vn5neH.

5. BELTRÃO, Jane Felipe. Quilombolas, Indígenas \& Violências: segredos, silêncios e conversas sobre crimes. Revista InSURgência. Brasília, ano 1, v. 1, n. 2, p. 6468, 2015. Disponível em: http://bit.ly/2GMTL1m. 
6. BELTRÃO, Jane Felipe. Direitos humanos e povos indígenas: um desafio para a Antropologia. In: COSTA, Paulo Sérgio Weyl A. (Org.). Direitos humanos em concreto. Curitiba, PR: Juruá Editora, 2008, p. 157-174.

7. BELTRÃO, Jane Felipe. Haraxare Krokti Ronore Konxarti e a vigilância do território Gavião Parkatêjê - Laudo antropológico. Humanitas, Belém, v. 18, n. 1, p. 101-111, 2002.

8. BELTRÃO, Jane Felipe. Gavião/Parkatêjê e a BR 222. Laudo antropológico. Belém, PA: UFPA, 1998.

9. BELTRÃO, Jane Felipe. Suruí/Aikewára e a BR 153. Laudo antropológico. Belém, PA: UFPA, 1998.

10. BELTRÃO, Jane Felipe; BARATA, Camille Gouveia Castelo Branco; ALEIXO, Mariah Torres. Corporeidades silenciadas: reflexões sobre as narrativas de mulheres violadas. Revista Direito e Práxis, v. 8, n. 1, p. 592-615, 2017. Disponível em: http://bit.ly/2AlvFF6.

11. BELTRÃO, Jane Felipe; MASTOP-LIMA, Luiza de Nazaré; MOREIRA, Hélio Luiz Fonseca. De vítimas a indiciados, um processo de ponta-cabeça: Suruí Aikewára versus Divino Eterno - Laudo antropológico. Espaço Ameríndio, UFRGS, v. 2, n. 2, p. 194-258, 2008. Disponível em: http://bit.ly/2BV78qB.

12. SANTOS, Lucy Woellner dos; ICHIKAWA, Elisa Yushie; CARGANO, Doralice de Fátima (Org.). Ciência, tecnologia e gênero: desvelando o feminino na construção do conhecimento. Londrina: IAPAR, 2006.

13. STAVENHAGEN, Rodolfo. Siete Tesis Equivocadas sobre América Latina. Sociología y Subdesarrollo. Ciudad de México: Nuestro Tiempo, 1981 [1965]. p. 15-84.

14. DOMINGUES, William César Lopes. Relatório acerca do trabalho como intérprete no caso dos gêmeos Arawete. Universidade Federal do Pará, 2017. (Inédito)

15. DOMINGUES, William César Lopes. Cachaça, concreto e sangue! Saúde, alcoolismo e violência. Povos indígenas no contexto da Hidrelétrica de Belo Monte. Dissertação (Mestrado em Antropologia), PPGA, Universidade Federal do Pará (UFPA), 2017. (Inédita)

16. GEERTZ, Clifford. O saber local: fatos e leis em uma perspectiva comparativa. In: GEERTZ, Clifford. O saber local: novos ensaios de Antropologia interpretativa. Rio de Janeiro: Vozes, 1998. p. 249-356.

17. OLIVEIRA, Assis da Costa. Trabalhadores e trabalhadoras de Belo Monte: Percepções sobre a exploração sexual e a prostituição. Altamira-PA: Comissão $\mathrm{Mu}-$ nicipal de Enfrentamento da Violência Sexual Contra Crianças e Adolescentes de Altamira, 2016. (Relatório de pesquisa) 
18. Notas para a formulação de uma política de garantia de direitos sexuais às crianças e aos adolescentes no cenário de grandes obras. In: PINHO, Vilma Aparecida; OLIVEIRA, Assis da Costa. Direitos infanto-juvenis e violência sexual em contexto de grandes obras: reflexões e perspectivas. Belém: GTR, 2014. Disponível em: http://www.neca.org.br/wp-content/uploads/Viol-Sexual-em-grandes-obras.pdf.

19. OLIVEIRA, Assis da Costa; PINHO, Vilma Aparecida. Relatório final do diagnóstico rápido participativo: enfrentamento da violência sexual contra crianças e adolescentes no município de Altamira-PA. Altamira, PA: s. e., 2013. Disponível em: http://docplayer.com.br/18917849-Rodas-de-direito-dialogo-empoderamento-e-prevencao-no-enfrentamento-da-violencia-sexual-contra-criancas-e-adolescentes.html. 